\title{
An economic evaluation of aripiprazole vs olanzapine adapted to the Italian setting using outcomes of metabolic syndrome and risk for diabetes in patients with schizophrenia
}

\author{
Giorgio L Colombo' \\ Mauro Caruggi² \\ Sergio Di Matteo' \\ Alessandro Rossi ${ }^{3}$ \\ 'S.A.V.E. Studi Analisi Valutazioni \\ Economiche, Milano, Italy; ${ }^{2}$ Università \\ degli Studi dell'Insubria, Varese, Italy; \\ ${ }^{3}$ Università de L’Aquila, Italy
}

\begin{abstract}
Objective: To evaluate the cost-effectiveness of aripiprazole and olanzapine in patients with schizophrenia.

Methods: Data from a double-blind, randomized study demonstrating the efficacy of aripiprazole and olanzapine were used to observe new incidence of metabolic syndrome (26-week therapy) and to model the risk of developing diabetes over 5 years of therapy. Cumulative incidence of metabolic syndrome was compared using Kaplan-Meier estimates; diabetes risk was estimated using a validated, general population risk-prediction model. Economic assessment was conducted from the third-party payer perspective by evaluating pharmacotherapy costs of treating schizophrenia and medical costs associated with treating adverse metabolic effects in a hypothetical cohort of 1000 patients. Resource utilization and costs were derived from the underlying study and published data, using a $3 \%$ rate to discount costs and benefits.

Results: For the patients switched from olanzapine to aripiprazole, treatment with aripiprazole was a dominant cost-saving strategy. Use of aripiprazole avoided 184 events of metabolic syndrome over 26 weeks of treatment, contributing to a real-world (RW) cost savings of $€ 2.53$ per patient and a total savings of approximately $€ 465.52$ over a 5 -year period. For the same cohort, the risk-prediction model indicated that 34 occurrences of diabetes could be avoided over 5 years, corresponding to a RW cost savings of $€ 56.86$ per patient and a total saving of approximately $€ 1,933.24$. These savings reflect avoided costs in treating adverse metabolic events and comparable costs in the acquisition of aripiprazole.
\end{abstract}

Conclusions: Maintenance aripiprazole therapy offers medical and economic benefits over olanzapine, reflected by reduced incidence of metabolic syndrome and diabetes and associated lower costs.

Keywords: schizophrenia, cost-consequences, apripiprazole, olanzapine, metabolic syndrome, diabetes

\section{Introduction}

Schizophrenia is a chronic psychiatric disorder characterized by hallucinations, delusions, negative symptoms, and disruptive thoughts and behaviors that typically arise during late adolescence or early adulthood (Thompson et al 2004). It affects approximately $1 \%$ of the US population (Ryan 1991) and is estimated to have a global prevalence of $0.14 \%-0.46 \%$ (Jablensky 2000 ).

The newer, second-generation antipsychotics (SGAs), also referred to as atypical antipsychotics, are thought to represent a significant advance over conventional first-generation antipsychotics (FGAs) in the treatment of patients with schizophrenia. 
Specifically, SGAs have a lower propensity to cause extrapyramidal symptoms (EPS) (eg, dystonia, tardive dyskinesia, akathisia and parkinsonism), which limit the safety of and long-term compliance with FGAs (Lakka et al 2002; Ryan and Thakore 2002). However, some SGAs have been associated with various adverse metabolic effects, such as glucose dysregulation, dyslipidemia and significant weight gain (Hughes et al 1986; de Leon et al 1995; Allison et al 1999; Susce et al 2005). Together with hypertension, these abnormalities comprise metabolic syndrome (Dixon et al 2000), which is associated with an increased risk for diabetes and coronary heart disease (CHD) (Lakka et al 2002; Ryan and Thakore 2002).

In addition to the increased risk for metabolic syndrome with certain SGAs, patients with schizophrenia already have increased risk factors for CHD, eg, smoking (Hughes et al 1986; de Leon et al 1995) and obesity (Allison et al 1999; Susce et al 2005). Moreover, patients with schizophrenia have a 5-fold higher risk of myocardial infarction than the general population (Enger et al 2004) and are also at increased risk for diabetes, independent of medication usage (Dixon et al 2000; Wirshing 2004). Recent findings from the CATIE study report a $40 \%$ prevalence of metabolic syndrome in patients with schizophrenia (McEvoy et al 2005). Consequently, the metabolic profiles of SGAs are important when considering treatment options for this patient population (Wirshing 2004). Given the significant social and economic costs associated with treating patients with diabetes (Lucioni et al 2000; Lucioni et al 2001; Ridker et al 2003), existing differences in metabolic profiles must be considered when choosing a pharmacological intervention for schizophrenia (Nasrallah 2002).

In Italy the average yearly total cost of a type 2 diabetes patient is about $€ 3,136$ per patient, while the estimated cost of the whole type 2 diabetes population is about $€ 5,423$ million. Direct costs account for $95.5 \%$ of the total. On the whole, they correspond to $6.65 \%$ of the total health care expenditure (public plus private) (Lucioni et al 2000, 2001). The substantial economic and social impacts of the disease result from high mortality rates (particularly among young adults), loss of employment, homelessness, family burden, and excessive use of inpatient health services, social services and housing services (Guest and Cookson 1999; Knapp 2000; Enger et al 2004; Folsom et al 2005).

The SGA aripiprazole has been shown to have clinical efficacy similar to that of other SGAs and FGAs (Kane et al 2002; Marder et al 2003; McQuade et al 2004). Moreover, aripiprazole has not been associated with the same degree of EPS observed with the older FGA haloperidol (Kane et al 2002; Marder et al 2003; Allochis et al 2008) or with weight gain observed with many of the other SGAs (McQuade et al 2004; ADA/APA/AACE/NAASO 2004).

The objective of this analysis was to conduct an economic evaluation of aripiprazole versus olanzapine for the treatment of schizophrenia in the Italian setting from a third-party payer perspective (Servizio Sanitario Nazionale - National Health Service [NHS]). Specifically, assuming equal clinical efficacy between the two agents, we will evaluate the pharmacotherapy costs of treatment for schizophrenia and the medical costs of treating adverse metabolic effects (eg, dyslipidemia, diabetes).

\section{Methods}

The model is developed to show the potential short-run and long-run cost savings in terms of incidence of metabolic syndrome and a lower risk of diabetes generated for a simulated cohort of 1000 patients with schizophrenia when treated with aripiprazole compared with olanzapine. These data were elaborated from a 26-week, multicenter, double-blind study comparing a flexible dose of aripiprazole $15-30 \mathrm{mg} /$ day $(\mathrm{n}=155)$ with a flexible dose of olanzapine $10-20 \mathrm{mg} /$ day $(n=159)$ on changes in weight and efficacy in the management of schizophrenia (McQuade et al 2004). The results of this study demonstrated that efficacy was comparable between treatment arms, as evidenced by sustained improvement in Positive and Negative Syndrome Scale (PANSS) scores, Clinical Global Impressions - Improvement scores, and in responder rates throughout the study. A sub-sample of patients (314 out of 317) from this trial (McQuade et al 2004) who had complete metabolic data in addition to the weight data was used to assess metabolic syndrome changes during the 26-week in-trial therapy period, and to model the risk of diabetes in the ensuing 5 years after the formal trial period.

Metabolic syndrome was defined as the presence or clinically meaningful exacerbation of three of five National Cholesterol Education Program (NCEP) Adult Treatment Panel (ATP) III risk factors (NCEP 2001). In addition, a combination definition that consisted of NCEP ATP III criteria and the clinically meaningful percentage change from baseline of those criteria were established (Table 1). Given that waist circumferences for most patients enrolled in the study were unavailable, the working definition involved the use of body mass index (BMI) rather than waist circumference to define abdominal obesity. This is supported by several metabolic studies in which BMI served as a surrogate for waist circumference (Ridker et al 2003; Sattar et al 2003; 
Table I Metabolic syndrome definitions

\begin{tabular}{ll}
\hline Adult Treatment Panel III Definition (Dixon et al 2000) & Modified Definition \\
\hline Waist circumference $\geq 40$ inches (male) and $\geq 35$ inches (female) & $>7 \%$ increases in BMl from baseline AND BMI $>25 \mathrm{~kg} / \mathrm{m}^{2 *}$ \\
$\mathrm{HDL}-\mathrm{C}<40 \mathrm{mg} / \mathrm{dL}$ (male) and $<50 \mathrm{mg} / \mathrm{dL}$ (female) & $>15 \%$ decrease in HDL-C from baseline AND HDL-C $<40 \mathrm{mg} / \mathrm{dL}^{\dagger}$ \\
$\mathrm{DBP} \geq 85 \mathrm{mmHg}$ or SBP $\geq 130 \mathrm{mmHg}$ & $\geq 8 \mathrm{mmHg}$ increase in DBP from baseline AND DBP $\geq 85 \mathrm{mmHg}$ \\
& OR \\
Fasting triglycerides $\geq 150 \mathrm{mg} / \mathrm{dL}$ & $\geq 12 \mathrm{mmHg}$ increase from baseline in SBP AND SBP $\geq 130 \mathrm{mmHg}{ }^{\ddagger}$ \\
Fasting plasma glucose $\geq 110 \mathrm{mg} / \mathrm{dL}$ & $\geq 15 \%$ increase from baseline from baseline in fasting triglycerides AND \\
& fasting triglycerides $\geq 150 \mathrm{mg} / \mathrm{dL}$ \\
\hline
\end{tabular}

*BMI was used rather than abdominal circumference because both are good predictors of metabolic outcomes and the former was directly related to the primary endpoint of the study. Waist circumference was not always available.

${ }^{\dagger}$ A simplification was made to consider values $<40 \mathrm{mg} / \mathrm{dL}$ for men and women.

$\$ 8 \mathrm{mmHg}$ and $12 \mathrm{mmHg}$ constitute the standard deviations for DBP and SBP measurements, respectively. Hence, any changes beyond these values may be considered true elevations in blood pressure.

¿Some patients did not have a fasting blood glucose measurement at baseline. For those patients, non-fasting values were used at baseline and subsequent visits.

Abbreviations: BMI, body mass index; HDL-C, high-density lipoprotein cholesterol; DBP, diastolic blood pressure; SBP, systolic blood pressure.

Ford 2004) and by a demonstrated positive correlation between these measures in another study (Lean et al 1995).

\section{Model structure}

In this model, treatment with either aripiprazole or olanzapine was assessed for metabolic disturbances over the 26 weeks of the study, and simulated to provide a comparison of estimated incidence rates of diabetes over 5 years, with corresponding estimated direct costs of care (Figure 1). A comparative economic evaluation was conducted based on aripiprazole and olanzapine having comparable efficacy. Post-hoc analyses of PANSS scores in the present study support this assumption.

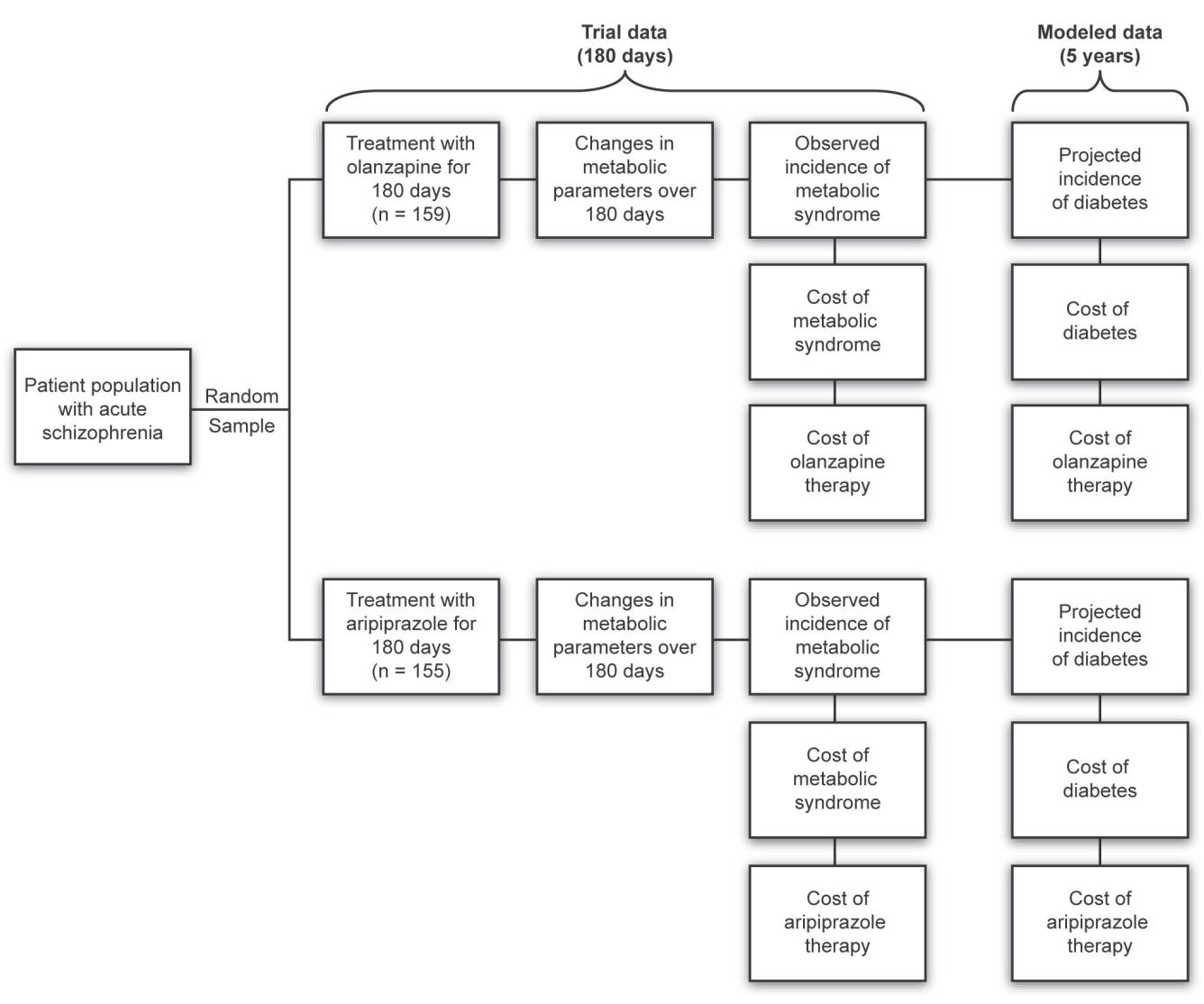

Figure I Overview of study design and decision analytic model structure. 
Besides assuming equal efficacy between aripiprazole and olanzapine, it was assumed that compliance with therapy was not affected by the occurrence of adverse events (AEs), including weight gain. Furthermore, the estimated risk for diabetes was based on changes from baseline to week 26 observed during the 26-week study period.

\section{Estimation of diabetes incidence}

The impact of therapy on the risk factors associated with the development of diabetes and its projected incidence were calculated for aripiprazole and olanzapine using a risk-prediction model developed by Stern et al (2002). This multivariate model used data from the San Antonio Heart Study (Burke et al 1999) to predict the risk of developing type 2 diabetes in 7.5 years. Variables in the model include patient characteristics (age, sex, ethnicity, and family history of diabetes) and laboratory values (fasting glucose, HDL, BMI, and systolic blood pressure). The authors found this risk-prediction model to be a viable alternative to the glucose tolerance test in predicting the risk of diabetes.

The current study incorporated patient data from the clinical study of McQuade et al (2004) into the diabetes riskprediction model developed by Ray et al (2004). The expected incidence of diabetes was projected for a 5-year period, but it was assumed that the measures affecting the outcomes of interest would not change further after week 26; it is actually likely that a medication that causes a metabolic parameter, such as body weight, to change over 26 weeks will continue to do so beyond that period (Nemeroff 1997; Henderson et al 2000).

To correct for any nominal differences in the variables at baseline between treatment arms, an analysis adjusting for baseline risk (analysis of covariance [ANCOVA]; proc. GLM, SAS version 8.1; SAS Institute, Cary, NC) was performed. After calculating the risk at 7.5 years $(r)$, annual risk levels at time $(t)$ between 0 and 5 years were approximated according to the following equation:

Diabetes risk $(t)=1-(1-r)^{(t / 7.5)}$

\section{Estimation of costs}

Economic analysis was conducted from the third-party payer perspective (NHS) by evaluation of the pharmacotherapy costs of treating schizophrenia and the direct costs of treating metabolic AEs and/or diabetes. Resource utilization and costs were derived from the clinical study and from published data (Lucioni et al 2000; Lucioni et al 2001). An annual discount rate of $3 \%$ was used to discount the annual costs and benefits beyond the first year of assessment.

Unit costs for antipsychotic drug were obtained from the Informatore Farmaceutico 2007 and were applied to the dosages/ strengths used. The daily costs were used to calculate drug costs for 26 weeks of therapy (Table 2). The cost of diagnosing and treating metabolic syndrome was estimated by assigning unit resource costs to physician visits, laboratory tests (eg, blood glucose and lipids), and drugs for treating hyperlipidemia (eg, statins, fibrates, niacin), hyperglycemia (oral antidiabetic agents) and hypertension (antihypertensives). The costs of diagnosing and treating the metabolic syndrome were estimated by assigning unit resource costs and drug costs (Table 3).

The cost of initializing treatment for metabolic syndrome, including office visits, tests and medications, was calculated for all patients. The direct cost estimate of treating diabetes was calculated according to the 1997 American Diabetes Association published estimates on medical treatment for patient with type 2 diabetes mellitus (Graves and Gillum 1996; Schappert 1996; Strahan 1996, 1997; ADA 1998); these data

Table 2 Direct medical costs for management of metabolic syndrome

\begin{tabular}{llll}
\hline Cost type & EUR $€$ & Comment and source \\
\hline Aripiprazole, $15 \mathrm{mg}$ & & $€ 5.02$ & Informatore Farmaceutico, 2007 \\
Olanzapine, $10 \mathrm{mg}$ & $€ 5.02$ & Informatore Farmaceutico, 2007 \\
Unit resource costs & Physician visits & $€ 23.00$ & 2006 National Tariff Nomenclator, Health Ministry \\
& Glucose tests & $€ 1.29$ & 2006 National Tariff Nomenclator, Health Ministry \\
& Lipid test & $€ 3.15$ & Includes HDL and triglycerides, 2006 National \\
& Hyperlipidemic agents & See comment & Tariff Nomenclator, Health Ministry \\
Drug costs & & Weighted average price/day for statins (€0.79), \\
& & & fibrates (€0.52) or niacin (€I.70) using weights \\
& & of $0.4,0.3$ and 0.3 , respectively (OSMED 2007)
\end{tabular}

Abbreviations: HDL, high-density lipoprotein. 
Table 3 Resource utilization: type II diabetes

\begin{tabular}{|c|c|c|c|c|c|}
\hline Diabetic treatment & Units & Unit cost & Value & Source & Comments \\
\hline Hospitalizations & $\begin{array}{l}\text { ALOS/No } \\
\text { of hosps }\end{array}$ & Per diem/DRG cost & $€ 4,774.13$ & DM I 2/09/2006 & DRG 294 \\
\hline $\begin{array}{l}\text { Emergency room } \\
\text { visits }\end{array}$ & No of visits & Cost per visit & $€ 34.50$ & DM I 2/09/2006 & Cod $89.7+50 \%$ \\
\hline \multicolumn{6}{|l|}{ Physician visits } \\
\hline Physician visit & No of visits & Cost per consult & $€ \mid 3.03$ & Lucioni et al 2000 and $200 \mathrm{I}$ & \\
\hline $\begin{array}{l}\text { Hospital outpatient } \\
\text { visit }\end{array}$ & No of visits & Cost per consult & $€ 23.00$ & DM I2/09/2006 & \\
\hline \multicolumn{6}{|l|}{$\begin{array}{l}\text { Test/Diagnostic } \\
\text { procedures }\end{array}$} \\
\hline Oral glucose test & No of tests & Cost per test & $€ 30.57$ & DM I2/09/2006 & Cod 90.28 .5 \\
\hline $\begin{array}{l}\text { Glycosylated } \\
\text { Hemoglobin }\end{array}$ & No of tests & Cost per test & $€ 10.59$ & DM I2/09/2006 & Cod 90.28.1 \\
\hline Urinalysis & No of tests & Cost per test & $€ 2.07$ & DM I2/09/2006 & Cod 90.44 .3 \\
\hline Vision test & No of tests & Cost per test & $€ 7.75$ & DM I2/09/2006 & Cod 95.09.1 \\
\hline \multicolumn{6}{|l|}{$\begin{array}{l}\text { Other health care } \\
\text { services }\end{array}$} \\
\hline Home health care & No of visits & Cost per visit & $€ 46.48$ & DM I 2/09/2006 & Cod 89.07 \\
\hline Hospice care & No of days & Cost per visit & $€ 201.42$ & $\begin{array}{l}\text { Deliberation of the Regional } \\
\text { Council of Lombardy } \\
\text { of } 13 / 12 / 06 \text { and nr. } 4239 \\
\text { of } 28 / 02 / 2007\end{array}$ & \\
\hline Nursing home care & No of days & Cost per visit & $€ 166.67$ & $\begin{array}{l}\text { Lombardy Region, Hospital } \\
\text { of Busto Arsizio, Varese }\end{array}$ & \\
\hline \multicolumn{6}{|l|}{ Drug therapy } \\
\hline Sulfonylureas & No of treatments & Cost per treated patient & $€ 0 .|83|$ & Lucioni et al 2000 and $200 \mathrm{I}$ & $€ /$ die \\
\hline Biguanides & No of treatments & Cost per treated patient & $€ 0.000 \mathrm{I}$ & Lucioni et al 2000 and 200I & $€ /$ die \\
\hline $\begin{array}{l}\text { Alpha-glucosidase } \\
\text { inhibitors }\end{array}$ & No of treatments & Cost per treated patient & $€ 0.68 \mathrm{I}$ & Lucioni et al 2000 and $200 \mathrm{I}$ & $€ /$ die \\
\hline Thiazodilinediones & No of treatments & Cost per treated patient & $€ 2.071$ & Lucioni et al 2000 and $200 \mathrm{I}$ & $€ /$ die \\
\hline Meglitinides & No of treatments & Cost per treated patient & $€ 0.036$ & Lucioni et al 2000 and $200 \mathrm{I}$ & $€ /$ die \\
\hline Insulin & No of treatments & Cost per treated patient & $€ 0.892$ & Lucioni et al 2000 and 200I & $€ /$ die \\
\hline
\end{tabular}

Abbreviations: ALOS, average length of stay; DM, Decreto Ministeriale [Ministerial Decree]; Cod, code; DRG, diagnosis-related group.

were modified taking into account the Italian CODE Study and the BRESCIA Study (Lucioni et al 2000, 2001; Scarcella et al 2006), which included inpatient and outpatient visits (including home health, hospice, and nursing home care and emergency room visits), tests, diagnostic procedures, other health services and diabetic drug treatment in Italy. The ISTAT medical care component of the Consumer Price Index was applied to approximate the time frame from which the current data originate at year 2007 (Italian inflation rates 2007).

\section{Statistical analysis}

Kaplan-Meier survival analysis was performed to estimate the cumulative incidence of metabolic syndrome (using the modified definition described in Table 1) over the course of the 26-week study. The log-rank test was used to test the difference between the survival functions. The risk for diabetes was estimated based on vital signs, laboratory values, and demographic data collected at the baseline and at week 26 visits using a validated, general population risk model developed by Stern et al (2002). To correct for any nominal differences in these factors between treatment groups at baseline, ANCOVA was performed to adjust for baseline risk. After calculating the risk at 7.5 years, annual risk levels between 0 and 5 years were approximated for each treatment group (Stern et al 2002).

\section{Sensitivity analysis}

Sensitivity analysis was performed according to clinical study (CT)-based and the RW dose regimens. Because this was a 
CT-based economic evaluation, the distributions of patients on different dose strengths (15-30 mg for aripiprazole, $10-20 \mathrm{mg}$ for olanzapine) during the 26-week study were used in this economic evaluation. This enabled us to estimate a plausible range of costs for the simulated patient sample observed in the study, based on CT dose regimens and on those reflecting RW regimens observed with patients in these dose ranges.

\section{Results}

The patient groups modeled had similar baseline demographic and metabolic characteristics (Table 4). Based on a KaplanMeier survival analysis, aripiprazole was associated with a lower incidence of metabolic syndrome and a delayed onset of development of metabolic syndrome compared with olanzapine (Figure 2). The log-rank test found a statistically significant difference $(p=0.011)$ between the two incidence functions with an estimated hazard ratio for aripiprazole versus olanzapine of 0.31 (95\% confidence interval [95\% CI]; 0.12, 0.77). At 26 weeks, the estimated cumulative incidence rates of new or worsening metabolic syndrome were $20.9 \%$ ( $\pm 7.8 \%$ [95\% CI]) for olanzapine and $9.2 \%( \pm 5.5 \%[95 \% \mathrm{CI}])$ for aripiprazole.

Based on the estimated incidence rates, costs associated with the treatment of metabolic syndrome and pharmacotherapy for schizophrenia were determined. Compared with olanzapine, aripiprazole use was found to be a dominant cost-saving strategy for treating schizophrenia. Based on the estimated absolute risk reduction of $18.4 \%$, aripiprazole use instead of olanzapine in a simulated cohort of 1000 patients resulted in the avoidance of 184 occurrences - new or worsening cases - of metabolic syndrome after the 26 weeks of therapy until 1 year; this risk reduction reflects the metabolic

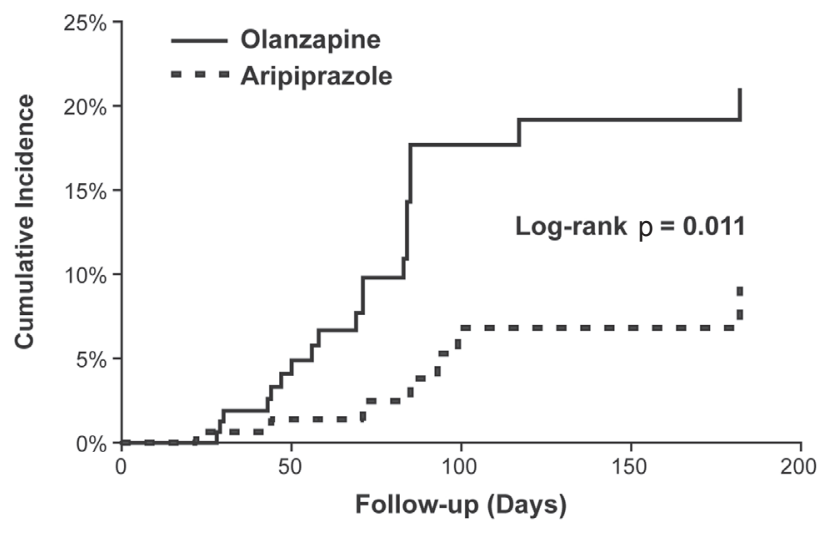

Figure 2 Kaplan-Meier plot of incidence of metabolic syndrome (cumulative incidence rates) in patients with acute schizophrenia treated with olanzapine or aripiprazole.

characteristics seen for each drug in clinical studies and observational studies (Newcomer 2005). Avoidance of these cases would contribute to a cost savings of $€ 2.53$ per patient and a total savings of approximately $€ 465.52$ (Table 5).

When considering diabetes prevention, aripiprazole was also a dominant cost-saving strategy. In the simulated cohort of 1000 patients, the values with aripiprazole for 26 weeks showed the avoidance of 34 events of diabetes over 5 years ( 18 in discounted scenario), resulting in a total cost savings of $€ 1,926.65$ (€966.77 in discounted scenario). In these scenarios, the cost savings reflect lower treatment costs of metabolic syndrome and diabetes, and lower aripiprazole acquisition costs.

\section{Discussion}

These results highlight the medical and economic benefits from maintenance therapy with aripiprazole compared with olanzapine, reflected by the reduced incidences of metabolic

Table 4 Characteristics of patients observed at baseline and change at Week 26 (LOCF) in the clinical study

\begin{tabular}{|c|c|c|c|c|c|c|c|}
\hline \multirow[b]{2}{*}{ Characteristic } & \multirow[b]{2}{*}{$\mathbf{n}$} & \multicolumn{3}{|c|}{ Aripiprazole $15-30 \mathrm{mg} /$ day $(\mathrm{n}=155)^{\mathrm{a}}$} & \multicolumn{3}{|c|}{ Olanzapine $10-20 \mathrm{mg} /$ day $(n=59)^{a}$} \\
\hline & & Baseline & $\begin{array}{l}\text { Difference } \\
\text { at week } 26\end{array}$ & $\mathbf{n}$ & Baseline & $\begin{array}{l}\text { Difference } \\
\text { at week } 26\end{array}$ & p-value \\
\hline Mean age, $y(S E)$ & 155 & $38.72(0.86)$ & - & 159 & $38.13(0.88)$ & - & - \\
\hline Male, n (\%) & 155 & $113(73 \%)$ & - & 159 & II3 (7I\%) & - & - \\
\hline Mean weight, kg (SE) & 136 & $80.82(1.84)$ & -0.86 & 138 & $80.42(1.85)$ & 3.35 & $<0.001$ \\
\hline Mean body mass index, kg/m² (SE) & 156 & $27.6(0.5)$ & -0.10 & 161 & $27.7(0.6)$ & 0.8 & $<0.001$ \\
\hline Mean fasting serum glucose, $\mathrm{mg} / \mathrm{dL}$ (SE) & 107 & $89.88(2.02)$ & 2.68 & 115 & $91.68(1.95)$ & 3.22 & NS \\
\hline Mean HbAlc, \% (SE) & 144 & $5.50(0.06)$ & 0.02 & 145 & $5.56(0.06)$ & 0.11 & NS \\
\hline Mean total cholesterol, mg/dL (SE) & 108 & $184.10(4.06)$ & -3.47 & 115 & I84.64 (3.94) & 9.18 & 0.009 \\
\hline Mean LDL-C, mg/dL (SE) & 108 & $107.83(3.47)$ & -1.43 & 114 & I I $0.33(3.38)$ & 5.04 & NS \\
\hline Mean HDL-C, mg/dL (SE) & 108 & $44.00(1.17)$ & 2.7 & 114 & $43.69(1.14)$ & -0.37 & 0.019 \\
\hline Mean fasting triglycerides, mg/dL (SE) & 108 & $162.44(10.68)$ & -20.20 & 114 & $159.36(10.39)$ & 17.07 & 0.012 \\
\hline
\end{tabular}

aNot all measures were available for every patient.

Abbreviations: LOCF, last observation carried forward; NS, non-significant; HbA Ic, glycosylated hemoglobin; HDL-C, high-density lipoprotein cholesterol; LDL-C, low-density lipoprotein cholesterol; SE, standard error. 
Table 5 Results: Direct medical costs and metabolic adverse effects avoided from over 26 weeks of aripiprazole therapy (model results based on McQuade et al 2004) - Base case scenario

\begin{tabular}{|c|c|c|c|c|c|c|c|}
\hline \multirow[b]{3}{*}{ Time horizon } & \multirow[b]{3}{*}{$\begin{array}{l}\text { Metabolic } \\
\text { events modeled }\end{array}$} & \multicolumn{6}{|l|}{ Outcomes } \\
\hline & & $\begin{array}{l}\text { Aripiprazole } \\
15 \mathrm{mg} / \mathrm{die}\end{array}$ & $\begin{array}{l}\text { Olanzapine } \\
10 \mathrm{mg} / \mathrm{die}\end{array}$ & $\begin{array}{l}\text { Aripiprazole } \\
\text { substitution }\end{array}$ & & & ICER \\
\hline & & $\begin{array}{l}\text { Total cost/ } \\
\text { schizophrenia } \\
\text { patient }\end{array}$ & & $\begin{array}{l}\text { Total cost* } \\
\text { avoided/ } \\
\text { schizophrenia } \\
\text { patient }\end{array}$ & & $\begin{array}{l}\text { Events } \\
\text { avoided// } 000 \\
\text { schizophrenia } \\
\text { patients }\end{array}$ & $\begin{array}{l}\text { Cost/metabolic } \\
\text { syndrome } \\
\text { avoided }\end{array}$ \\
\hline 26-week therapy & $\begin{array}{l}\text { Metabolic } \\
\text { syndrome }\end{array}$ & $€ 1,619.36$ & $€ I, 621.89$ & $-€ 2.53$ & Cost saving & 184 & $-€ \mid 3.79$ \\
\hline 5 years & $\begin{array}{l}\text { Type } 2 \text { diabetes } \\
\text { (undiscounted) }\end{array}$ & $€ 7,936.55$ & $€ 7,993.41$ & $-€ 56.86$ & Cost saving & 34 & $-€ I, 678.18$ \\
\hline 5 years & $\begin{array}{l}\text { Type } 2 \text { diabetes } \\
\text { (discounted } 3 \% \text { ) }\end{array}$ & $€ 7,3 \mid 5.83$ & $€ 7,368.42$ & $-€ 52.59$ & Cost saving & 18 & $-€ 2,860.52$ \\
\hline
\end{tabular}

*Includes cost of antipsychotic therapy and the costs of treating metabolic syndrome and diabetes for the patients with these adverse effects.

syndrome and diabetes, and lower total costs associated with aripiprazole treatment. Even though the efficacy of aripiprazole and olanzapine was found to be comparable in the original clinical trial (McQuade et al 2004), this analysis found aripiprazole to be more cost effective than olanzapine when metabolic side effects and their related treatment costs were accounted for. In this study, treatment costs (attributed to fewer metabolic AEs) and drug acquisition costs were lower with aripiprazole use.

The present analysis also found reduced incidence of new and worsening metabolic syndrome in patients treated with aripiprazole than those treated with olanzapine. The consequent projected risk for diabetes was also lower in aripiprazole-treated patients. These results are consistent with those of other studies in which olanzapine is associated with an increased attributable risk for diabetes over background rates (Newcomer 2005; Koro et al 2002; Leslie and Rosenheck 2004; Lambert et al 2005). In contrast, the incidence of metabolic syndrome and the projected risk for diabetes are not significantly different between aripiprazole and placebo (Weiden et al 2003; L'Italien et al 2006). This suggests that the increased risk for diabetes projected in this study for patients on olanzapine may be due to some intrinsic quality of that drug, whereas aripiprazole-treated patients showed an incidence similar to the background rate for diabetes among patients with schizophrenia in general. Risk projections for diabetes presented previously were based on changes in metabolic parameters observed over 26 weeks (McQuade 2004) and were not extrapolated beyond that period, probably underestimating the full long-term benefit of aripiprazole. However, it must be pointed out that McQuade's study is a large comparative atypical study designed to show non-inferiority of aripiprazole versus olanzapine in over

Table 6 Sensitivity analysis: dose die increasing for aripiprazole and olanzapine

\begin{tabular}{|c|c|c|c|c|c|}
\hline \multirow[b]{3}{*}{ Time horizon } & \multirow[b]{3}{*}{ Metabolic events modeled } & \multicolumn{4}{|l|}{ Outcomes } \\
\hline & & $\begin{array}{l}\text { Aripiprazole } \\
20 \mathrm{mg} / \mathrm{die}\end{array}$ & $\begin{array}{l}\text { Olanzapine } \\
15 \text { mg/die }\end{array}$ & $\begin{array}{l}\text { Aripiprazole } \\
\text { substitution }\end{array}$ & \\
\hline & & $\begin{array}{l}\text { Total cost/ } \\
\text { schizophrenia patient }\end{array}$ & & $\begin{array}{l}\text { Total cost* avoided/ } \\
\text { schizophrenia patient }\end{array}$ & \\
\hline 26-week therapy & Metabolic syndrome & $€ 2,428.03$ & $€ 2,430.80$ & $-€ 2.76$ & Cost saving \\
\hline 5 years & Type 2 diabetes (undiscounted) & $€ 11,830.19$ & $€ 11,888.16$ & $-€ 57.97$ & Cost saving \\
\hline 5 years & Type 2 diabetes (discounted 3\%) & 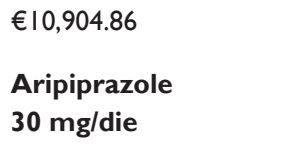 & $\begin{array}{l}€ 10,958.47 \\
\text { Olanzapine } \\
20 \mathrm{mg} / \mathrm{die}\end{array}$ & $-€ 53.61$ & Cost saving \\
\hline 26-week therapy & Metabolic syndrome & $€ 3,236.71$ & $€ 3,239.48$ & $-€ 2.76$ & Cost saving \\
\hline 5 years & Type 2 diabetes (undiscounted) & $€ 15,723.83$ & $€|5,78| .80$ & $-€ 57.97$ & Cost saving \\
\hline 5 years & Type 2 diabetes (discounted 3\%) & $€ \mid 4,493.88$ & $€ \mid 4,547.49$ & $-€ 53.61$ & Cost saving \\
\hline
\end{tabular}


700 subjects. In contrast with these results, we have to note that, according to a study by McCue (2007), olanzapine was significantly more effective than aripiprazole: the relevance of these results must be considered in the context of certain limitations of our analysis.

In our simulation, BMI was used as reference parameter to assess the impact of metabolic syndrome and conversion to waist circumference was performed. It must be noted that the relationship between these two adiposity measures may not be so straightforward, as shown by Faulkner et al (2007), who developed a schizophrenia-specific conversion system from BMI to abnormal waist. The etiology of the increased prevalence of type 2 diabetes mellitus in psychiatric disorders is uncertain, and although it might be due to the weight gain associated with atypical antipsychotic agents, this hypothesis should be regarded cautiously, especially in light of the fact that schizophrenia may be an independent risk factor for diabetes mellitus (Ryan et al 2003; Graham et al 2008). Consequently, our simulation should probably be updated based on these considerations, though more robust clinical trials would be necessary to gain more insights into this question.

Estimated costs of therapy with both agents assumed $100 \%$ compliance and an unchanged average daily dose for 5 years; chronic diseases associated with metabolic syndrome other than diabetes were not included in the cost calculations. Finally, the doses used do not reflect RW regimens of the two drugs in clinical practice; treatment with RW doses might lead to different risks for metabolic consequences, although published studies showing a link between diabetes onset and RW use of olanzapine do not report a dose-dependent risk (Koro et al 2002; Sernyak et al 2002). Nonetheless, the application of an RW dose would probably result in higher cost savings with aripiprazole, assuming a dose-independent AE profile, as RW dosing is increased relatively more for olanzapine than for aripiprazole (Citrome et al 2007), resulting in a larger increase in medication cost for olanzapine. It must be pointed out that the model used in this study has a limitation that depends on the lack of information on aripiprazole's behavior in terms of long-term treatment. If aripiprazole clinical efficacy is related to an increase in RW dosing over time that is proportionally superior to that of olanzapine, the results of this study could be reversed, with olanzapine being more cost-effective. On the contrary, if aripiprazole use beyond the period considered does not increase more than or is the same as that of olanzapine, our economic analysis would prove aripoprazole's advantage over olanzapine from a medical and economic point of view. To be able to confirm either of the two hypotheses, a drug-utilization study for aripiprazole would be necessary.

Because of the difficulty in estimating the costs associated with weight gain (eg, use of weight-lowering adjunct therapy) from the payer's perspective, these costs were not considered in this economic evaluation. However, weight gain and the indirect costs associated with it are certainly not inconsequential. Moreover, weight gain has a potential impact on metabolic syndrome, triglyceride levels, hypertension, CHD, stroke, and diabetes (Kurzthaler and Fleischhacker 2001; Brown 1998). In addition to these health risks among patients with schizophrenia, excessive weight gain can also cause quality-of-life impairment, increased relapse associated with non-compliance, and social withdrawal because of the stigma of obesity (Kurzthaler and Fleischhacker 2001).

The relevance of these results must be considered in the context of certain limitations. It should be emphasized that this work represents a cost-consequence analysis. The comparative study from which the incidence of metabolic syndrome was derived demonstrated a reduced incidence of new or worsening metabolic syndrome with aripiprazole than olanzapine. If metabolic syndrome was not prevented or treated, it was assumed that diabetes would develop in the projected number of patients. Finally, since the data used to develop our model were obtained from a study carried out in the US, one may doubt how representative these data might be for European patients (eg, different ethnicities). Nevertheless, this is a first attempt and may be regarded as a first step for developing studies more targeted to the European context.

The estimated avoidance of diabetes is a projection that must be confirmed in a prospective long-term study. Another limitation is that the issue of persistence was not included in this model. The possibility of discontinuing or switching drugs - events that could possibly change the predicted risk of metabolic syndrome or diabetes - was not considered in this analysis. In conclusion, the use of aripiprazole can avoid incidences of metabolic syndrome and potentially diabetes, thereby improving patient health and lowering healthcare costs; the present data suggest that aripiprazole may be a beneficial and cost-effective alternative to olanzapine, and more appropriate for patients at greatest risk of metabolic complications.

\section{Acknowledgments}

The study was financially supported by Bristol-Myers Squibb S.r.1., Rome, Italy. The authors would like to thank Sergio Di Matteo (S.A.V.E. Studi Analisi Valutazioni Economiche, 
Milan, Italy) for statistical support and Sara Ratti (S.A.V.E. Studi Analisi Valutazioni Economiche, Milan Italy) for editorial assistance.

\section{Disclosures}

None of the authors has any conflicts of interest to disclose.

\section{References}

[ADA/APA/AACE/NAASO] American Diabetes Association, American Psychiatric Association, American Association of Clinical Endocrinologists, North American Association for the Study of Obesity. 2004. Consensus development conference on antipsychotic drugs and obesity and diabetes. American Diabetes Association; American Psychiatric Association; American Association of Clinical Endocrinologists; North American Association for the Study of Obesity. Diabetes Care, 27:596-601.

[ADA] American Diabetes Association. 1998. Economic consequences of diabetes mellitus in the US in 1997. Diabetes Care, 21:296-309.

Allochis G, Cavallaro R, Milano W, et al. 2008. Bisogni irrisolti nel trattamento della schizofrenia: ruolo di aripiprazolo. Giornale Italiano di Psicopatologia, 14:88-104.

Allison DB, Fontaine KR, Heo M, et al. 1999. The distribution of body mass index among individuals with and without schizophrenia. $J$ Clin Psychiatry, 60:215-20.

Brown GD. 1998. The biosynthesis of steroids and triterpenoids. Natural Product Reports, 15:653-96.

Burke JP, Williams K, Gaskill SP, et al. 1999. Rapid rise in the incidence of type 2 diabetes from 1987 to 1996: results from the San Antonio Heart Study. Arch Intern Med, 159:1450-6.

Citrome L, Jaffe A, Levine J. 2007. Datapoints: The ups and downs of dosing second-generation antipsychotics. Psychiatr Serv, 58:11.

de Leon J, Dadvand M, Canuso C, et al. 1995. Schizophrenia and smoking: an epidemiological survey in a state hospital. Am J Psychiatry, 152:453-5.

Dixon L, Weiden P, Delahanty J, et al. 2000. Prevalence and correlates of diabetes in national schizophrenia samples. Schizophr Bull, 26:903-12.

Enger C, Weatherby L, Reynolds RF, et al. 2004. Serious cardiovascular events and mortality among patients with schizophrenia. J Nerv Ment Dis, 192:19-27.

Faulkner G, Cohn T, Remington G, et al. 2006. Body mass index, waist circumferences and quality of life in individuals with schizophrenia. Schizophr Res, 90:174-8.

Folsom DP, Hawthorne W, Lindamer L, et al. 2005. Prevalence and risk factors for homelessness and utilization of mental health services among 10,340 patients with serious mental illness in a large public mental health system. Am J Psychiatry, 162:370-6.

Ford ES. 2004. The metabolic syndrome and mortality from cardiovascular disease and all-causes: findings from the National Health and Nutrition Examination Survey II Mortality Study. Atherosclerosis, 173:309-14.

Graham KA, Cho H, Brownley KA, et al. 2008. Early treatment-related changes in diabetes and cardiovascular disease risk markers in first episodi psychosis subjects. Schizophr Res, 101:287-94.

Graves EJ, Gillum BS. 1996. 1994 summary: National Hospital Discharge Survey. Adv Data, 278:1-12.

Guest JF, Cookson RF. 1999. Cost of schizophrenia to UK Society. An incidence-based cost-of-illness model for the first 5 years following diagnosis. PharmacoEconomics, 15:597-610.

Health Ministry. 2006a. National Tariff Nomenclature. Nomenclatore delle Prestazioni di assistenza specialistica ambulatoriale. Ministero della Salute.

Health Ministry. 2006b. Hospital DRG tariffs. Tariffa Unica Convenzionale, National DRG Tariff. Ministerial Decree DM 12/09/2006.
Health Ministry. 2007. OSMED, Osservatorio sui farmaci dell'Agenzia italiana del farmaco (AIFA - Italian Drug Agency).

Henderson DC, Cagliero E, Gray C, et al. 2000. Clozapine, diabetes mellitus, weight gain, and lipid abnormalities: A five-year naturalistic study. Am J Psychiatry, 157:975-81.

Hughes JR, Hatsukami DK, Mitchell JE, et al. 1986. Prevalence of smoking among psychiatric outpatients. Am J Psychiatry, 143:993-7.

Italian inflation rates. 2007. [online] Accessed July 2007. URL: http://www. istat.it/prezzi/precon/rivalutazioni

Jablensky A. 2000. Epidemiology of schizophrenia: the global burden of disease and disability. Eur Arch Psychiatry Clin Neurosci, 250:274-85.

Kane JM, Carson WH, Saha AR et al. 2002. Efficacy and safety of aripiprazole and haloperidol versus placebo in patients with schizophrenia and schizoaffective disorder. J Clin Psychiatry, 63:763-71.

Knapp M. 2000. Schizophrenia costs and treatment cost-effectiveness, Acta Psychiatrica Scandinavica, 102(Suppl 407):15-18(4).

Koro CE, Fedder DO, L'Italien GJ, et al. 2002. Assessment of independent effect of olanzapine and risperidone on risk of diabetes among patients with schizophrenia: population based nested case-control study. $B M J$, $325: 243-7$.

Kurzthaler I, Fleischhacker WW. 2001. The clinical implications of weight gain in schizophrenia. J Clin Psychiatry, 62:32-7.

Lakka HM, Laaksonen DE, Lakka TA et al. 2002. The metabolic syndrome and total and cardiovascular disease mortality in middle-aged men. JAMA, 288:2709-16.

Lambert BL, Chou C-H, Chang K-Y, et al. 2005. Antipsychotic exposure and type 2 diabetes among patients with schizophrenia: a matched case-control study of California Medicaid claims. Pharmacoepidemiol Drug Saf, 14:417-25.

Lean ME, Han TS, Morrison CE. 1995. Waist circumference as a measure for indicating need for weight management. BMJ, 311:158-61.

Leslie DL, Rosenheck RA. 2004. Incidence of newly diagnosed diabetes attributable to atypical antipsychotic medications. Am J Psychiatry, 161:1709-11.

L'informatore farmaceutico 2007. Medicinali, Masson-Elsevier.

L'Italien GJ, Casey DE, Kan HJ, et al. 2007. Comparison of metabolic syndrome incidence among schizophrenia patients treated with aripiprazole versus olanzapine or placebo. J Clin Psychiatry, 68:1510-6.

Lucioni C, Garancini MP, Massi-Benedetti M, et al. 2000. The social cost of type 2 diabetes in Italy: the CODE-2 study. PharmacoEconomics Italian Research Articles, 2:1-21.

Lucioni C, Mazzi S, Serra G. 2001. Drug costs and and treatment patterns in patients with type-2 diabetes mellitus: results from CODE-2 study. PharmacoEconomics - Italian Research Articles, 3:1-14.

Marder SR, McQuade RD, Stock E, et al. 2003. Aripiprazole in the treatment of schizophrenia: safety and tolerability in short-term, placebocontrolled trials. Schizophr Res, 61:123-36.

McCue RE, Waheed R, Urcuyo L, et al. 2006. Comparative effectiveness of second-generation antipsychotics and haloperidol in acute schizophrenia. Br J Psychiatry, 189:433-40.

McEvoy JP, Meyer JM, Goff DC, et al. 2005. Prevalence of the metabolic syndrome in patients with schizophrenia: Baseline results from the Clinical Antipsychotic Trials of Intervention Effectiveness (CATIE) schizophrenia trial and comparison with national estimates from NHANES III. Schizophr Res, 80: 19-32.

McQuade RD, Stock E, Marcus R, et al. 2004. A comparison of weight change during treatment with olanzapine or aripiprazole: results from a randomized, double-blind study. J Clin Psychiatry, $65: 47-56$

Nasrallah HA. 2002. Pharmacoeconomic implications of adverse effects during antipsychotic drug therapy. Am J Health Syst Pharm, 59(Suppl 8):S16-S21.

Nemeroff CB. 1997. Dosing the antipsychotic medication olanzapine. J Clin Psychiatry, 58:45-9. 
[NCEP] National Cholesterol Education Program. 2001. Executive Summary of The Third Report of The National Cholesterol Education Program (NCEP) Expert Panel on Detection, Evaluation, and Treatment of High Blood Cholesterol In Adults (Adult Treatment Panel III). JAMA, 285:2486-97.

Newcomer JW. 2005. Second-generation (atypical) antipsychotics and metabolic effects: a comprehensive literature review. CNS Drugs, 19:1-93.

Ray S, Corey-Lisle PK, Cislo PR, et al. 2004. An economic evaluation of aripiprazole compared to olanzapine based on metabolic side-effect profile. Eur Neuropsychopharmacol, 14(Suppl 3):S279.

Ridker PM, Buring JE, Cook NR, et al. 2003. C-reactive protein, the metabolic syndrome, and risk of incident cardiovascular events: an 8-year follow-up of 14719 initially healthy American women. Circulation, 107:391-7.

Ryan MC, Thakore JH. 2002. Physical consequences of schizophrenia and its treatment: the metabolic syndrome. Life Sci, 71:239-57.

Ryan MC, Collins P, Thakore JH. 2003. Impaired fasting glucose tolerance in first-episode, drug-naïve patients with schizophrenia. Am J Psychiatry, 160:284-9.

Ryan PM. 1991. Epidemiology, etiology, diagnosis, and treatment of schizophrenia. Am J Hosp Pharm, 48:1271-80.

Sattar N, Gaw A, Scherbakova O, et al. 2003. Metabolic syndrome with and without $\mathrm{C}$-reactive protein as a predictor of coronary heart disease and diabetes in the West of Scotland Coronary Prevention Study. Circulation, 108:414-9.
Scarcella C, Indelicato A, Levaggi R, et al. 2006. The cost of diabetes: the Brescia's experience. PharmacoEconomics - Italian Research Articles, 8:95-103.

Schappert SM. 1996. National Ambulatory Medical Care Survey: 1994 summary. Adv Data, 273:1-18.

Sernyak MJ, Leslie DL, Alarcon RD, et al. 2002. Association of diabetes mellitus with use of atypical neuroleptics in the treatment of schizophrenia. Am J Psychiatry, 159:561-6.

Stern MP, Williams K, Haffner SM. 2002. Identification of persons at high risk for type 2 diabetes mellitus: do we need the oral glucose tolerance test? Ann Intern Med, 136:575-81.

Strahan GW. 1996. An overview of home health and hospice care patients: 1994 National Home and Hospice Care Survey. Adv Data, 274:1-8.

Strahan GW. 1997. An overview of nursing homes and their current residents: data from the 1995 National Nursing Home Survey. Adv Data, 280:1-12.

Susce MT, Villanueva N, Diaz FJ, et al. 2005. Obesity and associated complications in patients with severe mental illnesses: a cross-sectional survey. J Clin Psychiatry, 66:167-73

Thompson JL, Pogue-Geile MF, Grace AA. 2004. Developmental pathology, dopamine, and stress: a model for the age of onset of schizophrenia symptoms. Schizophr Bull, 30:875-900.

Weiden PJ, Waldeck R, Tafesse E, et al. 2003. Aripiprazole is not associated with increased diabetes risk: a long-term model [poster]. American Psychiatric Association 156th Annual Meeting, San Francisco, CA.

Wirshing DA. 2004. Schizophrenia and obesity: impact of antipsychotic medications. J Clin Psychiatry, 65(Suppl 18):S13-26. 